\title{
RICARDO PERONA: EL ESTATUTO SUBJETIVO DEL CONCEBIDO EN EL ORDENAMIENTO JURÍDICO ITALIANO ${ }^{1}$
}

\section{THE SUBJECTIVE STATUS OF THE UNBORN UNDER THE ITALIAN LE- GAL ORDER}

RESUMEN: La ponencia intenta describir, en sus aspectos esenciales, el estatuto subjetivo del concebido dentro del ordenamiento italiano. A través de una recapitulación de las pertinentes disposiciones normativas y de unos relevantes fallos jurisprudenciales, se concluye que el concebido, aunque no se pueda considerar a lleno título una "persona", constituye un buen ejemplo de los nuevos tipos de "sujetos" que caracterizan la juridicidad contemporánea.

ABSTRACT: The paper tries to describe, in its fundamental elements, the subjective status of the unborn under the Italian legal order. After a review of the applicable norms and some relevant judgments, the conclusion is that the unborn cannot be considered a "person" in all senses but, still, constitutes a good examples of the new "subjects" that characterize today's law.

PALABRAS CLAVE: Concebido - Sujeto de derecho - Persona

KEYWORDS: Unborn - Legal Subject - Person

\section{LA CUESTIÓN Y SU RELEVANCIA}

Objetivo de la presente ponencia es describir, en sus aspectos esenciales, el estatuto subjetivo del concebido en el ordenamiento italiano.

El tema se inscribe y evidencia su particular relevancia y actualidad en el contexto teórico más amplio de las evoluciones que la noción de subjetividad jurídica está viviendo en el panorama del derecho contemporáneo, tanto desde el punto de vista de la reflexión doctrinal como en términos de evoluciones del derecho positivo y de la jurisprudencia, a nivel nacional e internacional.

${ }^{1}$ Doctor en Derecho por la Universidad de Pisa. Docente de Teoría general del derecho en la Universidad del Piamonte Oriental (año académico 2016-2017). Director del Instituto Jurídico Internacional de Turín (www.igito.it). Contacto: riccardo.perona@igito.it. 
Al respecto, cabe señalar que la "persona" —así como tradicionalmente considerada, en cuanto persona física o moral- sigue siendo protagonista a la hora de hablar de los "sujetos" del derecho - como titulares o centros de imputación de derechos y obligaciones-, pero ha perdido su exclusividad. De hecho, nuevas "entidades" se presentan, al considerar el tema, a la atención del estudioso, a empezar, por ejemplo, de la naturaleza, ya considerada en textos constitucionales y legislativos como titular de unos derechos propios (el caso de la Constitución de Ecuador es, al respecto, el más significativo y citado) ${ }^{2}$.

En este marco se inscriben también las nuevas tendencias de configuración conceptual de la posición subjetiva del concebido, las cuales, entonces, muestran su relevancia no solamente desde la perspectiva de la bioética, sino también desde el punto de vista de la teoría general y de la dogmática jurídica ${ }^{3}$.

\section{EL ENFOQUE ESPECÍFICO DEL PRESENTE TRABAJO}

Por supuesto, la intrínseca brevedad de la presente contribución no permite un análisis exhaustivo de la materia considerada, aunque en los límites ya indicados -es decir, con referencia al caso del ordenamiento italiano.

Sin embargo, es posible ofrecer un resumen sintético de la misma tomando en cuenta las disposiciones normativas relevantes (párr. 3) y unos fundamentales desarrollos de la jurisprudencia, sobre todo de la Corte de Casación (párr. 4), para intentar, en conclusión, una discusión crítica del cuadro global que emerge de la recapitulación operada (párr. 5).

\section{LAS DISPOSICIONES NORMATIVAS}

La posición subjetiva del concebido no es objeto de una disciplina orgáni-

${ }^{2}$ Sobre tales temas véase Perona, R., "Sobre la subjetividad jurídica del medio ambiente: apuntes teóricos", en: Velandia Canosa, Eduardo Andrés - Quiroga Natale, Edgar Andrés (directores científicos), Derecho procesal constitucional: garantía jurisdiccional del medio ambiente en el derecho comparado (Bogotá, VC Editores - Ediciones Nueva Jurídica, 2016), 329.

${ }^{3}$ Baldini, G., Persona e familia nell'era del biodiritto. Verso un diritto comune europeo per la bioetica (Firenze, Firenze university Press, 2015); en este volumen, D'Amico, M., "Il concepito e il diritto a nascere sani: profili costituzionali alla luce della decisione della Corte di cassazione (n. 16754 del 2012)", 169; Cirillo, G. P., "L'inizio della vita umana nel sistema giuridico italiano" (www.giustizia-amministrativa.it, 2010); Buffone, G., La tutela della vita nascente. Lo statuto giuridico del concepito al confine fra Soggetto e Persona (www.altalex.it, 2007); Biscontini, G., Ruggeri, L., La tutela della vita nascente. A proposito di un recente progetto di legge (Napoli, E.S.I., 2003); Baldini, G., "II nascituro e la soggettività giuridica" (Dir. fam e pers., 2000, 334); Busnelli, F.D., "Lo statuto del concepito" (Dem. dir., 1988, 231). 
ca en el ordenamiento italiano, sino que tiene que ser delineada por el intérprete a través de una atenta reconstrucción de diferentes disposiciones.

Cabe al respecto subrayar, antes que todo, que una específica tutela o un particular reconocimiento de la posición del concebido no se encuentran a nivel de las expresas previsiones constitucionales. Sin embargo, diferentes principios se consideran indirectamente relevantes al respecto: reconocimiento y garantía de los derechos inviolables del hombre (art. 2 Cost.), tutela de los hijos y respectivos deberes de los padres (art. 30), tutela de la maternidad (art. 31, art. 37), tutela de la salud (art. 32).

Unas referencias mucho más puntuales a la condición del concebido -0 del feto- se encuentran, en cambio, a nivel legislativo.

En este sentido, según lo establecido en el artículo primero, apartado primero, del código civil italiano — promulgado en el año 1942_, la capacidad jurídica se adquiere desde el momento del nacimiento. Por consecuencia, al concebido no se le reconoce tal capacidad.

Además, según lo dispuesto en el apartado 2 del mismo artículo, los derechos que la ley reconoce al concebido están subordinados al evento del nacimiento. Tal previsión indica, entonces, que el feto ya está de alguna manera considerado por el ordenamiento jurídico, en particular al fin de la atribución de unos derechos, pero, al mismo tiempo, limita nuevamente el alcance de los mismos, en relación a su titularidad, a través de una condición suspensiva que reconoce como momento fundamental el nacimiento.

El concebido es también interesado por las disposiciones del código concernientes las sucesiones y las donaciones. En particular, el "nascituro" (la persona que va a nacer) tiene la capacidad de suceder (art. 462), junto, sin embargo, a los hijos de la persona viviente en el momento de la muerte del testador, aunque todavía no concebidos (ibídem). Asimismo, se pueden revocar las disposiciones testamentarias establecidas por quien ignoraba la existencia de un hijo o descendiente concebido (art. 687). El "nascituro" puede también recibir donaciones (art. 784); sin embargo, en este caso también, la misma capacidad se le reconoce a los hijos de la persona viviente en el momento de la muerte del testador, aunque todavía no concebidos (ibídem).

En cambio, y por su parte, el código penal —del año 1931- prevé como delito la conducta de la mujer que, durante el parto, determina la muerte del feto en razón de condiciones de abandonamiento material y moral ligadas al parto mismo (art. 578).

Otras indicaciones se pueden traer de la ley no. 194 del año 1978, concerniente la interrupción voluntaria del embarazo: de hecho, en el caso que haya la posibilidad de una vita autónoma del feto, tal interrupción es admitida solamente en el caso de peligro grave para la vida de la mujer y es necesario, en cualquier caso, adoptar todas las medidas necesarias para salvaguardar la vida del feto mismo (art. 7, apartado 3).

Más recientemente, la ley no. 40 del año 2004, concerniente la procreación médicamente asistida, explicita su finalidad de tutelar "los derechos de to- 
dos los sujetos interesados, incluso el concebido". Según una lectura literal de tal disposición, entonces, el concebido sería a lleno título un sujeto del ordenamiento jurídico.

\section{LA EVOLUCIÓN DE LA JURISPRUDENCIA}

\section{a) Premisa}

A la luz de lo antedicho, emerge claramente que tanto la doctrina como la jurisprudencia tienen que manejar, dentro del sistema jurídico italiano, un cuadro normativo particularmente inorgánico y complejo a la hora de reconstruir precisamente el estatuto subjetivo del concebido y solucionar consecuentemente los casos concretos que se presenten.

Al respecto, cuatros fallos de la Corte de Casación de las últimas décadas parecen particularmente interesantes, en consideración de la importancia que han asumido en escandir las etapas fundamentales de la evolución jurisprudencial sobre el tema y de las cuestiones teóricas contemporáneamente abordadas en las respectivas motivaciones.

\section{b) La sentencia de la Corte de Casación no. 14488 del año 2004}

En el caso decidido con la sentencia no. 14488 del año $2004^{4}$, en particular, se discute de la posibilidad de reconocerle tanto a los padres cuanto al hijo el resarcimiento del daño por el nacimiento del hijo mismo en condiciones de enfermedad, en consecuencia del hecho que los médicos no habían avisado los padres de la posibilidad de la transmisión al dicho hijo de la enfermedad de la madre (talasemia).

La Corte, en este caso, reconoce el resarcimiento a los padres pero no al hijo, y la argumentación desarrollada a tal último propósito es muy relevante a nuestros fines.

En particular, y a lado de una interesante referencia de derecho comparado, sobre todo al ordenamiento francés, la Corte observa que, si hay un derecho a nacer (sano), no se puede considerar existente un derecho a no nacer (o a no nacer excepto que en condiciones sanas), en cuanto, según lo establecido por el citado artículo 1 del código civil, tal derecho no tendría titular (o sea, más

${ }^{4}$ Sobre tal decisión: Giovanardi, E., Brevi note sull'ammissibilità del danno da "vita indesiderata" (Giur. it., 2005, 6); Feola, M., "Essere o non essere: la Corte di Cassazione e il danno prenatale" (Danno e Resp., 2005, 4, 379); Rizzieri, A., "La responsabilità del ginecologo per non avere accertato che il nascituro era affetto da patologia invalidante" (Resp. civ., 2005, 7, 590). 
precisamente, no lo tendría antes del nacimiento, mientras que, después, el mismo derecho no sería más configurable). De igual manera, el derecho citado habría un titular sólo en consecuencia de su violación.

Además, sigue argumentando la Corte, el ordenamiento italiano tutela el concebido en la perspectiva del "nacer" y no del "no nacer". Por último, admitiendo el derecho de que se habla, no sería claro si y cuando la madre de un concebido enfermo sería obligada a abortar para evitar una responsabilidad frente al mismo hijo.

\section{c) La sentencia de la Corte de Casación no. 10741 del año 2009}

El caso decidido con la sentencia no. 10741 del año $2009^{5}$ concierne nuevamente la posibilidad de resarcir el hijo nato enfermo, pero en consecuencia de la suministración de un fármaco a la madre por parte del médico sin adecuada información sobre los posibles efectos dañosos del mismo para el feto.

En este caso, la Corte reconoce el resarcimiento al hijo, afirmando que eso no determina ninguna contradicción con la decisión del año 2004, en consideración de la evidente diferencia de los casos. De hecho, la sentencia de 2009 precisa que el resarcimiento no habría sido reconocido si la información del médico hubiese sido pretendida solamente en perspectiva funcional a la eventual interrupción del embarazo.

De una manera muy relevante a nuestros fines, la Corte, argumentando su decisión, llega a considerar el concebido efectivamente un "sujeto", o sea un ser dotado de una autónoma subjetividad - aunque no llena como la de una "persona" en sentido estricto y técnico-. Tal subjetividad resulta a su vez coligada a la titularidad, que no se le puede negar al concebido, de unos derechos propios, por ejemplo a la vida y a la salud.

\section{d) La sentencia de la Corte de Casación no. 16754 del año 2012}

El caso decidido con la sentencia no. 16754 del año $2012^{6}$ concierne una

${ }^{5}$ Sobre tal decisión:, Cacace, S., "Figli indesiderati nascono. il medico in tribunale" (Danno e Resp., 2009, 12, 1167); Di Ciommo, F., "Giurisprudenza-normativa e "diritto a non nascere se non sano". la corte di cassazione in vena di revirement?" (Danno e Resp., 2010, 2, 144); Viola, L., "Il nascituro ha il diritto di nascere sano, ma non quello di non nascere" (Resp. civ., 2009, 8-9, 706).

${ }^{6}$ Sobre tal decisión: Carbone, V., "La legittimazione al risarcimento spetta direttamente al concepito nato malformato per errata diagnosi" (Corriere Giur., 2012, 11, 1291); Muccioli, N., "Diagnosi prenatale inesatta e responsabilità del medico" (Contratti, 2013, 6, 563); Cacace, S., II giudice "rottamatore" e l'enfant préjudice (Danno e Resp., 2013, 2, 139); Monateri, P. G., II danno al nascituro e la lesione della maternità cosciente e responsabile (Corriere Giur., 2013, 1, 45); D'Amico, M., "Il concepito e il diritto a nascere sani: profili costituzionali alla luce della decisione della Corte di cassazione (n. 16754 del 2012)", cit. 
situación análoga a la decidida con la sentencia del año 2004. Con el fallo de 2012, sin embargo, el resultado de aquella sentencia se tumba, y la Corte reconoce al hijo el resarcimiento del daño por nacimiento en condiciones de enfermedad.

En realidad, lo que sorprende de esta decisión es que a la dicha solución no le corresponde el reconocimiento de la subjetividad del concebido, sino que, precisamente al revés, la sentencia critica tal reconocimiento, así como de alguna manera afirmado con el fallo de 2009.

En la opinión de la Corte, de hecho, la protección del concebido no presupone necesariamente su cualificación en términos subjetivos. Más bien, intentar tal cualificación sólo pone problemas conceptuales sin solución. En particular, el punto dirimente es que la normativa italiana, a la hora de prever la interrupción del embarazo - con una ley que la Corte Constitucional ha considerado no incompatible con la Constitución-, claramente impide considerar el concebido como sujeto, porque en este caso la vida del mismo no podría considerarse sucumbiente en un adecuado balanceo de intereses con los relativos a los problemas de salud de la madre.

Por tales razones, la Corte propone considerar al feto no como sujeto, sino como objeto de tutela por parte del ordenamiento jurídico (mientras que las fórmulas de la mencionada ley no. 40 del año 2004 serían solamente impropias expresiones adoptadas por una inadecuada técnica normativa).

En esta perspectiva, la posibilidad de resarcir el daño del hijo por nacimiento en condiciones de enfermedad se puede afirmar, en la opinión de la Corte, en razón de la "propagación intersubjetiva de los efectos diacrónicos del ilícito". Eso significa que el derecho del cual es necesario partir es él a la procreación consciente y responsable que puede reconocerse solamente a la madre. Este es el derecho violado por el hecho ilícito, el cual, sin embargo, tiene una potencialidad de propagación en la esfera jurídica del hijo -aunque solamente después del nacimiento y precisamente en virtud de la personalidad jurídica que él adquiere en consecuencia del nacimiento mismo. En tal sentido, el hecho del médico que no informa de una manera adecuada la madre, determina un daño futuro en la esfera jurídica de él que será la persona (nacida) enferma.

\section{e) La sentencia de la Corte de Casación no. 25767 del año 2015}

El caso decidido con la sentencia no. 25767 del año $2015^{7}$ concierne la

\footnotetext{
${ }^{7}$ Sobre tal decisión: Piraino, F., "I confini della responsabilità civile e la controversia sulle malformazioni genetiche del nascituro: il rifiuto del c.d. danno da vita indesiderata" (Nuova Giur. Civ., 2016, 3, 450); Russo, M., "Omessa informativa sulle condizioni per l'interruzione della gravidanza: spunti in materia di legittimazione e prova" (Giur. It., 2016, 6, 1392); Cacace, S., "Commento" (Danno e Resp., 2016, 4, 349); di Bilò, G., "Nascita e vita indesiderate: i contrasti giurisprudenziali all'esame delle Sezioni Unite" (Corriere Giur., 2016, 1, 41).
} 
demanda de resarcimiento presentada por los padres de una niña, también en nombre de la misma, por nacimiento en condiciones de enfermedad (síndrome Down) en consecuencia de la inadecuada información de los médicos a la madre, la cual, por eso, no abortó.

La Corte, con la dicha sentencia, niega la posibilidad de tal resarcimiento, de esta manera retomando la perspectiva que inspiró la decisión de 2004, aunque con unas precauciones.

En particular, en la opinión del Colegio, la persona nacida puede abstractamente considerarse titular del derecho a demandar el resarcimiento. De hecho, no se ponen problemas en consecuencia de la anterioridad del hecho ilícito al nacimiento, en cuanto, después del nacimiento, para el sujeto surge, junto a la capacidad jurídica, el derecho al resarcimiento. En avanzar tal argumentación, la Corte se refiere en particular a lo decidido en un precedente mucho más remoto, la sentencia no. 11503 del año 1993.

Sin embargo, según sigue el itinerario motivacional de la Corte, lo que tiene que examinarse de una manera profundizada en el caso concreto es la naturaleza del daño que la persona demanda ser resarcido - es decir, lo que en los ordenamientos anglosajones se llamaría daño por wrongful life.

En tal sentido $-\mathrm{y}$ haciendo también referencia a la experiencia de otros Países (Estados Unidos, Reino Unido y Alemania) - la Corte argumenta que el daño consistiría, en el caso presente, en la vita misma, mientras que la ausencia de daño correspondería a la ausencia de vida. Eso, sin embargo, determina una contradicción insuperable, en cuanto un daño, en general, se supone lesivo de un bien de la vida, y la ausencia de vida sin duda no se puede considerar un bien de la vida.

Argumentar en sentido opuesto, de hecho, llevaría a una reificación del ser humano, que tendría valor sólo -en términos peligrosamente eugenésicos- en consideración de su integridad psíquica y física.

\section{DISCUSIÓN Y CONCLUSIÓN}

La recapitulación de las disposiciones normativas y de los fallos más relevantes propuesta hasta aquí nos permite unas consideraciones conclusivas de síntesis y reflexión crítica.

Al respecto, cabe señalar que la complejidad del cuadro legislativo y la evolución no uniforme de la jurisprudencia, sin duda, hacen difícil reconstruir de una manera totalmente clara y definida el estatuto subjetivo del concebido. Sin embargo, unos elementos en tal dirección se pueden obtener.

En tal sentido, se puede decir que el sistema jurídico italiano atribuye al concebido una posición absolutamente peculiar e interesante, en cuanto no lo califica como "persona" a todos los efectos, pero tampoco lo considera entera- 
mente irrelevante a los fines del reconocimiento de sus derechos e intereses.

El discurso, cabe subrayar, lleva implicaciones al mismo tiempo teóricas y prácticas, en cuanto de la calificación subjetiva del concebido depende la posibilidad del mismo de ejercer sus derechos (después del nacimiento, pero en relación a hechos ocurridos anteriormente), sobre todo en tema de resarcimiento del daño.

Clásicamente, las soluciones ofrecidas por la reflexión se articulan alrededor de la distinción entre persona y sujeto. De tal manera, entendiendo a este último come concepto más amplio e idóneo a cualificar también "seres" que no sean -o no sean todavía - personas en sentido técnico, la cuestión relevante es entender si el concebido, pacíficamente no persona a lleno título, ya tenga su propia subjetividad: lo que la jurisprudencia ha venido afirmando incluso expresadamente (fallo del 2009).

Más recientemente, en cambio, los desarrollos jurisprudenciales (véanse las citadas sentencias de 2012 y 2015) tienden a abandonar tales conceptualizaciones, al entender el concebido como objeto de tutela (fallo de 2012) o directamente evitando el problema de su cualificación (fallo de 2015) y prefiriendo, en ambos casos, centrarse sobre los derechos (y la posibilidad de acción judicial) de la persona después del nacimiento (aunque en relación a hechos ocurridos anteriormente).

Sin embargo, parece a quien escribe que, desde el punto de vista teórico y dogmático, la cuestión de la calificación del concebido en términos de sujeto o no siga siendo relevante y que, en realidad, una forma aunque atenuada de subjetividad no se pueda que reconocer como subsistente para el concebido.

De hecho, a pesar de todo, a la hora de admitir el resarcimiento del daño de una persona para hechos ocurridos cuando todavía la misma persona no era nacida, sino solamente concebida, parece demasiado difícil argumentar que se considere su posición anterior al nacimiento en términos de simple "objeto". En tal sentido, la sentencia de 2012 parece demasiado "kelseniana" en evitar los discursos subjetivos: por supuesto, como precisamente nos enseña la obra de Kelsen ${ }^{8}$, no es imposible concebir a la dimensión objetiva como la única relevante - de manera que los mismos derechos de libertad sean "así llamados" pero en realidad no existentes-, pero no es esta la dirección en que se ha movido, por lo menos desde la segunda mitad del siglo pasado, la historia del derecho.

En aquel planteamiento objetivista, el riesgo eugenésico de la que nos habla la sentencia de 2015 parece bien evidente y no es casual que precisamente a aquella impostación le corresponda una ampliación de los hechos considerados como resarcibles.

De hecho, el reconocimiento de un derecho a no nacer -en términos directos o como efecto de una propagación intersubjetiva de los efectos diacróni26.D.

\footnotetext{
${ }^{8}$ Kelsen, H., Allgemeine Staatslehre, Berlin, Springer, 1925, sobre todo párr. 11, 13, 14,
} 
cos del ilícito de un "derecho" (o sea, nos parece, en términos simplemente perifrásticos)— sólo puede admitirse en una perspectiva de reificación del ser humano, considerado no como persona o sujeto sino como cosa u objeto.

En tal sentido, en la opinión del autor, la última jurisprudencia mencionada tiene que saludarse con favor, al mismo tiempo pudiéndose confirmar que, en el ordenamiento italiano, al concebido se le pueda reconocer la titularidad de una forma de subjetividad y que, entonces, el mismo constituya un buen ejemplo de los nuevos tipos de sujetos que la juridicidad contemporánea ofrece a lado de la tradicional "persona".

\section{BIBLIOGRAFÍA CITADA} 334)

Baldini, G., "Il nascituro e la soggettività giuridica" (Dir. fam e pers., 2000,

Baldini, G., Persona e familia nell'era del biodiritto. Verso un diritto comune europeo per la bioetica (Firenze, Firenze university Press, 2015)

Biscontini, G., Ruggeri, L., La tutela della vita nascente. A proposito di un recente progetto di legge (Napoli, E.S.I., 2003)

Buffone, G., La tutela della vita nascente. Lo statuto giuridico del concepito al confine fra Soggetto e Persona (www.altalex.it, 2007)

Busnelli, F.D., "Lo statuto del concepito" (Dem. dir., 1988, 231)

Cacace, S., "Commento" (Danno e Resp., 2016, 4, 349); di Bilò, G., "Nascita e vita indesiderate: i contrasti giurisprudenziali all'esame delle Sezioni Unite" (Corriere Giur., 2016, 1, 41)

Cacace, S., "Figli indesiderati nascono. il medico in tribunale" (Danno e Resp., 2009, 12, 1167)

Cacace, S., Il giudice "rottamatore" e l'enfant préjudice (Danno e Resp., 2013, 2, 139)

Carbone, V., "La legittimazione al risarcimento spetta direttamente al concepito nato malformato per errata diagnosi" (Corriere Giur., 2012, 11, 1291)

Cirillo, G. P., "L'inizio della vita umana nel sistema giuridico italiano" (www.giustizia-amministrativa.it, 2010)

D'Amico, M., "Il concepito e il diritto a nascere sani: profili costituzionali alla luce della decisione della Corte di cassazione (n. 16754 del 2012)", en: Baldini, G., Persona e familia nell'era del biodiritto. Verso un diritto comune europeo per la bioetica (Firenze, Firenze university Press, 2015), 169

Di Ciommo, F., "Giurisprudenza-normativa e "diritto a non nascere se non sano". la corte di cassazione in vena di revirement?" (Danno e Resp., 2010, 2, 144) 
Feola, M., "Essere o non essere: la Corte di Cassazione e il danno prenatale" (Danno e Resp., 2005, 4, 379)

Giovanardi, E., Brevi note sull'ammissibilità del danno da «vita indesiderata» (Giur. it., 2005, 6)

Kelsen, H., Allgemeine Staatslehre, Berlin, Springer, 1925

Monateri, P. G., il danno al nascituro e la lesione della maternità cosciente e responsabile (Corriere Giur., 2013, 1, 45)

Muccioli, N., "Diagnosi prenatale inesatta e responsabilità del medico" (Contratti, 2013, 6, 563)

Perona, R., "Sobre la subjetividad jurídica del medio ambiente: apuntes teóricos", en: Velandia Canosa, Eduardo Andrés - Quiroga Natale, Edgar Andrés (directores científicos), Derecho procesal constitucional: garantía jurisdiccional del medio ambiente en el derecho comparado (Bogotá, VC Editores Ediciones Nueva Jurídica, 2016), 329

Piraino, F., "I confini della responsabilità civile e la controversia sulle malformazioni genetiche del nascituro: il rifiuto del c.d. danno da vita indesiderata" (Nuova Giur. Civ., 2016, 3, 450)

Rizzieri, A., "La responsabilità del ginecologo per non avere accertato che il nascituro era affetto da patologia invalidante" (Resp. civ., 2005, 7, 590)

Russo, M., "Omessa informativa sulle condizioni per l'interruzione della gravidanza: spunti in materia di legittimazione e prova" (Giur. It., 2016, 6, 1392)

Viola, L., "Il nascituro ha il diritto di nascere sano, ma non quello di non nascere" (Resp. civ., 2009, 8-9, 706) 